\section{Business Analytics and Sociomateriality: A Study on the Practice of Revenue Management in an Airline Company}

\author{
Claudia Xavier Cavalcanti ${ }^{1}$ \\ cxcavalcanti@gmail.com | (D) 0000-0002-8799-2203 \\ Alfredo Rodrigues Leite da Silva ${ }^{1}$ \\ alfredoufes@gmail.com | (DD.0000-0002-5943-1185
}

\begin{abstract}
The aim of this article is to address the Business Analytics (BA) practice based on the sociomateriality approach within the Revenue Management (RM) context of an airline. The study proposes that BA is an active engagement process which is set between analysts and business managers according to their sociomaterial imbrication with analytical data and tools, which areused to generate new insights. The discussion is substantiated by the theoretical articulation of BA as applied to RM based on the sociomateriality approach, which acknowledges the synergetic interaction between human and material dimensions by keeping their distinction from intentionality. The empirical investigation followed a qualitative design supported by nonparticipatory observation, interview and document research, which were the data collection techniques. The collected data was analyzed through spiral analysis associated with a practices' description and analyses framework. Results have supported the BA proposition by evidencing the human/material dimension entanglement to produce BA-practice specificities.
\end{abstract}

\section{KEYWORDS}

Business Analytics, Revenue Managements, Sociomateriality, Imbricationof agencies
${ }^{1}$ Universidade Federal do Espírito Santo, Vitória, ES, Brasil 


\section{INTRODUCTION}

The analytical approach, or Business Analytics (BA) has been in the mainstream lately because it allows managers to deal with great volumes of information (Cosic, Shanks, \& Maynard, 2015). It has been calling the attention of scholars, business managers and consultants given its operation and strategical potential for several economic sectors, including financial services, insurance, retail, health and production (Dubey et al., 2016). One of its applications lies on supporting Revenue Management (RM), which is applied to help predict consumers' behavior at microeconomic level and to optimize product availability and pricing in order to maximize revenues (Cross, 1997). Revenue Management (RM) is often used in operations based on relatively fixed profiles, such as those adopted by hotels and airlines (Slack, Chambers, \& Johnston, 2008). Many professionals in these sectors are in charge of developing RM, which has been consolidated as a relevant topic for the operational-research field (Talluri \& Ryzin, 2004).

The current article approaches sociomateriality in the BA practice applied to RM by acknowledging the relevance of BA discussions and of its application to RM. The study is an attempt to question the small emphasis given on sociomateriality by researchers in the BA-studies field and to clarify its implication to BA practices - which, by the way, are not addressed in this study field, despite the emphasis given on materiality.

According to BA studies, this approach becomes holistic in the data management sphere (Ashrafi, Ravasan, Trkman, \& Afshari, 2019) given the tools adopted to analyze, mine, and visualize data in order to improve decision-making processes (Davenport, Harris, \& Shapiro, 2010). Researchers have been neglecting the interaction between people and technology, since they only emphasize technology and its applications, even when they acknowledge that people are part of this process (Jordan \& Ellen, 2009); in other words, the material dimension (technology) prevails in the BA-studies field. This approach limits the possibility of better understanding that organizations can be overloaded with data, but can also have a hard time using such data for business purposes (Soejarto \& Chandler, 2015).

The present study applies and articulates a new approach, which was not yet adopted for BA studies, as an alternative for the social/material dimension imbrication (Leonardi, 2012). Based on this approach, the aim of the current article is to help better understanding of the BA practice from the sociomateriality viewpoint, within the RM context of an airline. Accordingly, such pathway revealed the implications of the mutual influence of the human/social material imbrications in BA technology, which was no longer addressed in studies in this scientific field. This approach helps researchers, and other interested parties, to better understand such implications and how to deal with them.

It was necessary conceptually improving the BA-studies field in order to address these implications and to reach the expected aim of the present study. The adopted approach was in compliance with the sociomateriality perspective, which resulted from the herein introduced theoretical articulations. Sharma, Mithas and Kankanhalli (2014) highlighted a gap in this scientific field by pointing out that researchers look forward to better understanding how the actions of people, equipment, and different software work together to generate new insights based on BA use. A new definition set for BA, which meets the sociomaterial perspective, was developed to fulfil the aforementioned gap.

The observed imbrication of people, equipment, and different software is substantiated by theoretical contributions that make it possible to understand that BA comprises people, processes and technologies to allow data collection and analysis for decision-making support (Jordan \& Ellen, 2009). This outcome is achieved if one acknowledges that this combination of factors also 
involves the human/technological material imbrication based on the sociomateriality perspective (Leonardi, 2011). Accordingly, it is possible, assuming that BA is an active engagement process involving analysts and business managers based on the sociomaterial imbrication of analytical data and tools used to generate new insights. The herein adopted sociomateriality approach was developed by Leonardi (2012, p. 21), according to whom "practice is a space where the social and material dimensions get entangled and produce empirically observable entities called technologies and organizations".

The empirical application of the herein developed articulation became clear when it was adopted to investigate how the BA practice can be applied to the RM context of an airline, based on the sociomateriality perspective.

The empirical investigation followed a qualitative design and data collection which was based on non-participatory observation, interviews and on documental analyses. The spiral analysis method (Creswell, 2013) combined to the practice and activity description framework was used for data analysis (Bispo, 2015).

This study showed that the BA technology provides elements to improve the potential of news actions, such as shorter time to generate reports based on previously reported data. Such element is related to restrictions imposed to some actions, such as lack of updated information from previous reports. The material dimension of BA emerges from its potentials and restrictions, since they entangle to the social dimension (analysts), which must deal with potentials like the faster generation of reports, and with restrictions, such as obsolete data. It may be possible to disrupt this perspective, by changing, or not changing, social routines and technology itself. This finding depicts the dynamics observed in the goals, social routines, and technologies of the assessed airline, which change from time-to-time.

Theoretical contributions of the present study lie on suggesting and applying a BA concept that made the sociomateriality dynamics part of BA-studies development. This concept clarified the relevant implications of the BA practice in the RM of the investigated airline, when it was empirically applied.

Acknowledging the BA sociomaterial practice, as applied to RM, provided material contributions that were taking into account to improve management processes applied to the organization's personnel and technologies. This was done by adopting a technology, or plaining and training contents, that included aspects related to the herein evidenced sociomaterial imbrications. In other words, an analyst can get prepared to better deal with the technologies adopted by the airline and with the restrictions and potentials that are part of the imbrication of its social routines and used technologies.

The theoretical aspects of sociomateriality in investigations focused on technology, its potential in BA studies and the new definition of BA were the elements substantiating the aforementioned contributions. The empirical investigation methods and their contexts, result analyses and conclusions are presented below.

\section{SOCIOMATERIALITY IN TECHNOLOGY STUDIES}

Studies focused on the relationship between the social and technical dimensions in organizations are new, although there are several approaches introducing important similarities and differences between these dimensions. Leonardi (2012) and Orlikowski (2009) point out the study by Trist and Bamforth (1951) among these research, because it was pioneering in applying the sociotechnical approach and influenced many studies that came after it, since their study showed changes in the coal-extraction technology, which have influenced miners' social structure and their reactions. 
These authors have indicated technologies and activities that have been currently applied by some miners as technical subsystems due to their main features. The aforementioned activities concern technical reactions from workers to socially change the used technologies; they included ways to define how to use the new technologies and who would use them.

According to Leonardi (2012), the concept described above is similar to the sociomaterial practice, which is based on the contemporary understanding of the sociomateriality viewpoint. However, this concept was not applied in further interpretations in other research conducted by these same authors. The presence of a social dimension in the technical subsystem was left aside, and no attention was paid to evidence that the technical definitions of tasks are also socially produced by workers. Oftentimes, the social production was only attributed to social subsystems, since it specifically heads toward aspects such as hierarchical status among workers, workers' power relationships, communication patterns, and identity, as well as refering to the relationship among workers as social group. Thus, the social subsystem placed itself in a position of duality with the technical subsystem.

Despite this duality, Leonardi (2012) showed that the social and material dimensions mutually influence each other in the seminal proposals by Trist and Bamforth (1951). This influence is often defined based on the contemporary sociomaterial viewpoint. However, they criticized the fact that such influence only suggests how the theoretical possibility was more influential, because of the understanding that the technical subsystem has prevailed in the sociotechnical approach; therefore, the social subsystem must be adjusted to the technical subsystem.

Contemporary studies have emerged from this, and other, influences; they have embodied the sociomaterial viewpoint and aimed at investigating aspects related to the technical and social subsystems. Authors such as Ciborra and Lanzara (1994), and Cardoso and Silva (2017), among others, investigated changes in technologies based on relationships in social groups and on an ontology substantiated by the human dimension. These researchers emphasized social actions and human interpretations, and put the materiality of a given technology in the background. However, they were criticized by Orlikowski (2009), for they did not adopt a relational ontology that neither favored the human dimension nor the material one. Such concern, and contributions from it, became the highlights in other studies based on the so-called sociomateriality.

The sociomateriality proposition outspread in the last decades as the perspective having the potential to assess technology, humans and organizations (Leonardi \& Barley, 2008). Authors have been advocating for its use to assess materializations associated with the emergence of metadata, social media and algorithms (Orlikowski \& Scott, 2015). The usefulness of this approach resulted from knowledge about the relational and performative ontological relationship in which objects and humans only exist when they engage in mutual interactions (Barad, 2003).

These ideas were widespread by organizational studies; they compose the so-called "material turn", which is focused on sociomateriality, on approaches contrary to the distinction between materiality and sociality, and between the social and material dimensions, or yet on the articulation of the material/social division. On one hand, there is the realism of the dimension, according to which the social and material dimensions are inseparable and do not have distinct natures (Orlikowski, 2007, 2009); on the other, there is critical realism, in which the social and material dimensions become sociomaterial when these two dimensions get entangled.

Orlikowski (2007, 2009) and Gherardi (2012), among others, highlight that, along with humans, materials are active elements of practice, their dimension lies on the relational distribution of elements. This practice model was inspired by studies on the Actor-Network Theory (ANT), which does not give ontological priority neither to humans nor to non-humans (Gherardi, 2012), 
since it treats both elements as a specific dimension, as things that can be used as a feature. The sense of dimension is conceived as the continuous attribute of everything and everyone, it does not have a defined time-spectrum in terms of producing something that has a beginning and an end, since the dimension itself is the mutual interaction of things for the world's reconfiguration; therefore, it is reasonable associating it with someone or something (Barad, 2003).

Leonardi (2013) criticizes this concept by inserting himself in the critical realism. He opted for articulating two dimension types based on the contributions by Pickering (1995, 2001), according to whom, there is a social dimension - the coordinated exercise of a group of people to form and perform its goals based on a given intention - and a material dimension - which happens through performativity, i.e., through the materiality of actions taken by the social dimension. According to him, materiality does not act to perform its own goals - it is not intentional; it does not stop technology from doing things that go beyond the social dimension control given the unpredictability of imbrications between dimensions.

Based on the aforementioned influence, the approach by Leonardi (2013) allows taking into consideration the differences observed between the material and social dimensions. He acknowledges that the 'dimension' is not something really held by a special group; thus, his concept gets close to the understanding about the realism of the dimension, but he disagrees with the idea that one must see the dimensions as configurations of the world, since there is the understanding that the concept of dimensions does not contribute to empirical studies. Instead of following such understanding, he advocates that studies must take into account two basic elements that overlap these two dimensions in the sociomateriality practice; each dimension has different features that get entangled by producing reconfigurations.

According to this different approach about the concept of dimension, Leonardi (2011) defines that the term dimension alone only indicates the existence of a feature; therefore, he advocates that it is mandatory to determine what characterizes such feature. He suggests that the human dimension lies on the individual's intention, which can be coordinated into a social dimension. He also states that the social dimension is both social and human, since it entangles to the materiality of technology because technology itself allows people to deal, or not, with the material dimension. Accordingly, the social/human imbrication accounts for interconnections set in sequences that are related to technologies and for, simultaneously, producing such interconnections as an empirical phenomenon observed by people throughout time. In other words, this process concerns an imbrication that, although continuous, is marked by temporality, since there is a time to begin and a time to end. These times are constantly generated, given the existing practices and organizations; they change within a time plane that must be taken into consideration when the aforementioned imbrication is investigated (Leonardi, 2013). There is always something in time that comes before the action; therefore, time is part of aspects of the action itself and of elements that concern its change or continuity (Mutch, 2013). This concept depicts the scene of objective time, which is defined by a number or by a time scale (minutes, hours...) that hosts the occurrence of something, as well as by the scene of subjective time, which refers to multiple interactions that involve the objective time and happen due to it. Leonardi (2011) suggests that the human and material dimensions are effective in producing results when they are unified through imbrication in a given time. Thus, the sense of time and imbrication allows keeping the difference between the human and material dimensions.

It must be clear that the imbrication metaphor is different from the sense of hybridism between the human and material dimensions set by Latour (1999) and observed in ANT. Latour (1999) argues that the human and material dimensions are undistinguishable, they are hybrids; therefore, 
action itself has no point of origin. Leonardi (2011) criticizes viewpoints such as this one, which address the patterns of social actions called by him "routines" and technologies as similar elements of dimensions. He advocates that routines are as social and material as technologies, but each one of them takes place in different social/human dimension imbrications; these elements are related to both dimensions and set the differences between them. By acknowledging such difference, it becomes possible to understand how changes in routines, technologies and organizations happen.

According to the aforementioned author, people decide how they respond to a given technology, but the human/social dimension imbrication is related to affordances and constraints imposed by the technology, due to interactions that affect results deriving from decisions made. Therefore, decisions made by individuals do not point out the human dimension domain, and the lack of such domain does not mean that the social and material dimensions are equal; they are different, but entangled in a process that defines future changes in routines and technologies.

This understanding guides the proposition defined in the present article, it completes the BA concept based on the discussion about the sociomateriality linked to it. Such discussion would contribute to the best understanding about the dynamics of changes in routines, technologies and organizations due to BA implementation. Therefore, the definition proposed by Leonardi (2012), which is summarized in Chart 1, was adopted in the present study.

\section{Chart 1}

Definitions adopted by Leonardi (2012) in studies about sociomateriality and technology

Materiality; Arrangements of physical and/or digital materials of an artefact that is presented in particular shapes, which go beyond local and time differences, and are important for users.

Sociomateriality: the composition of a specific set of activities that join materiality to institutions, rules, discourses and to all other phenomena often defined as "social".

Sociomateriality practice: the space where several (social) human and material dimensions get entangled. (Also called "technical subsystem").

Social Agency: Human intension coordinated and partially formed to respond to the material dimension's perceptions about a technology.

Material agency: the ways through which the materiality of a given technology acts. The material dimension is activated when human beings approach a technology based on specific intentions and decide what elements of its materiality must be used at a given moment.

Sociotechnical System: The recognition of a recursive way (non-simultaneous) of abstract social constructions and of a technical infrastructure that includes technology materiality and the responses observed by people.

Source: Leonardi (2012, p. 42).

Based on Chart 1, it is possible to state that, according to Leonardi (2012), social dimensions (which are human dimensions in plural coordinates) and material dimensions, although different from each other, can get entangled to the materiality of the sociomaterial practice within a sociotechnical system. This concept acknowledges the sociomateriality in order to evidence that the materiality of technology belongs to the social realm; therefore, the social realm is not just an inert, limited and stable artefact (Leonardi, 2013).

People find constraints and affordances in this realm due to interactions between people and technologies; thus, these interactions do not belong to these people or technologies, but to something relational. The constraints of a technology are the ways through which people realize that they can be stopped from reaching a specific goal by using a technology or system, and its affordances are the potential of actions resulting from this technology or system, and from what they can result in (Majchrzak \& Markus, 2012). Intentions deliberated by individuals in 
the human dimension are determined by these relationships. The deliberation process can be explained by what DiMaggio (1997) identifies as the deliberative cognition approach addressed in psychological studies; according to him, this cognition is different from automatic cognition.

According to the aforementioned author, deliberative cognition refers to the replacement of pre-set thinking patterns by new ones, which must be based on critics and reasoning. He explains that automatic cognition uses these patterns in a different way, as they provide shortcuts that make them often used in daily life tasks. They simplify the way to deal with incomplete information about events and objects by allowing assumptions applied to automatically complete the missing information.

According to DiMaggio (1997), the deliberation process tends to fail in rejecting automatic cognition given the ease resulting from the shortcuts it provides; therefore, he addresses how the deliberation process takes place, despite these shortcuts. He introduces three possibilities in this discussion, he states that these shortcuts are approached in Psychology and are useful for the sociological approach. These possibilities explain deliberation manifestations: 1) the attention paid to a specific issue; 2) the motivation resulting from the dissatisfaction with a moral matter or with the status quo; 3) failure in dealing with new stimuli due to the use of current schemes of thinking.

Discussion about deliberations based on the human/material dimension imbrication allows for observing that affordances and constraints refer to contexts linked to possibilities 1 and 2 . Dispositions provided by technology's affordances allow the human dimension to start paying attention to previously ignored issues; it is done by using elements such as a report about price variations between market competitors. Constraints of a given technology, such as the use of a chart traditionally used every seven days to monitor prices exerted by competitors - which can change on a daily basis -, in regards to the use of such technology in a current routine.

People define the way they will entangle to the material or social dimensions in order to produce new routines (humans) or new technologies when they face the constraints and affordances of a given technology. This endless process leads to new sociomaterial imbrications to new affordances or constraints in order to develop new forms of action (Leonardi, 2011).

Many authors have addressed the sense of imbrication focused on the role played by the social and material dimensions and by their entanglement based on this discussion (Zorina \& Avison, 2011). This article articulates this discussion to use its potential in the development of the BA-studies field, since it allows better understanding of the dynamics of changes in routines, technologies and BA-related organizations. Therefore, it is necessary address a new discussion about the BA concept and providing a new concept that must be in compliance with the acknowledgment of BA sociomateriality, as proposed below.

\section{SOCIOMATERIALITY CONTRIBUTIONS TO BA STUDIES AND TO ITS RECONCEPTION}

BA is often seen from three different perspectives in its study field (Evans, 2016): - the descriptive perspective, which concerns data categories, features, consolidation, and classification to turn such data into useful information for the best understanding and analysis of business performance; - the predictive perspective, which takes into account past performance analysis to predict the future; - and the prescriptive perspective, which uses optimization to identify and recommend the best alternatives to minimize or maximize any goal. 
BBR

17

426

Based on such perspectives, one can say that, as BA got more relevant in the last decade, it has been posing challenges linked to non-technical factors, such as leaderships and culture (Davenport, 2017). However, the prevailing research available closely relates BA to what can be called a "technology of exogenous profile" (Orlikowski, 2009); in other words, this research advocates for the idea that BA has a deterministic function, since they focus on the enhancement of its deterministic performance, mainly when it comes to the applied technologies (Appelbaum et al., 2017, Ashrafi et al., 2019, Aydiner et al, 2019, Bronzo et al., 2013, Chen $\&$ Nath, 2018, Wang \& Byrd, 2017).

Accordingly, BA is defined as the extensive use of data, statistical and quantitative analyses, and of explanatory and predictive models that are based on a management type focused on facts and data for decision-making purposes (Davenport \& Harris, 2007). The relationship among people, processes, and technology is addressed in terms of operational aspects, even when BA is seen as a combination of three elements: people, processes and technology. These operational aspects influence data collection, analysis, and transformation, since they substantiate the managerial decision-making process (Jordan \& Ellen, 2009). This concept sees humans as part of BA, but most often it sees them in terms of their role as operators. Therefore, the aim of the present article is to complete this concept - which acknowledges the presence of human beings in the process - by adding the human/material dimension imbrication to it, based on the sociomateriality viewpoint (Leonardi, 2011). Hence, BA was herein defined as an active engagement process set between analysts and business managers based on the sociomaterial imbrication of the data and analytical tools used to give birth to new insights.

The herein advocated concept broadens the understanding about how changes in the BA practice take place by readdressing such practice based on the human and material dimensions, which get entangled to compose it (Leonardi, 2013). The empirical part of the present article, for instance, will be substantiated by BA application to the RM of an airline. If a traditional approach found in the BA-studies field was herein applied to investigate the dynamics behind RM in the airline sector, the study would only concern the selling of the right seat to the right client, at the right moment and for the right price (Donovan, 2005). This process means a rational goal that demands parametrization and customization (Strauss, Klein, \& Steinhardt, 2018); therefore, the aim of the study would likely be to enhance these aspects or the technologies associated with them.

On the other hand, based on the herein proposed approach, the parametrization and customization of technological artefacts are only part of a more complex imbrication process. The intentionality of the human dimension can search for the parametrization of the BA system applied to RM; however, the human dimension interacts with technology's constraints and affordances during this search - this process leads to possible changes in the BA technology applied to RM. It can also cause changes in the technology's material dimension and generate new constraints and affordances. This continuous process does not necessarily lead to the results expected by the intentionality of human dimension, which have started the flow in the flexibility of the BA technology applied to RM.

It is necessary to observe the involved goals and technologies in order to better understand such flexibility. RM in the assessed airline aims at finding a balance between selling tickets at promotional prices to overbooking the aircraft seats and selling full price tickets to just book part of the seats in it (Donovan, 2005). Such goal is achieved through techniques used to allocate limited resources to a whole variety of clients in order to optimize total revenue or revenue from investment capacity (Netessine \& Shumsly, 2002). 
It is possible to understand that the BA practice in RM demands report elaboration and adjustments by taking the aforementioned process to the sociomateriality scope, as well as parametrizations that take place in systems and tables and constant consultations, i.e., this field's analysts need to make decisions based on what they have available in material artefacts. Therefore, the contributions of the critical realism by Leonardi (2013) is a coherent way to go deeper in the sociomateriality of BA application to RM and in showing how it is practiced, since it advocates for the constant imbrication of human and material dimensions in the use of technology.

The present proposition was adopted in this empirical study to help better understanding the Business Analytics (BA) practice within the Revenue Management (RM) context of an airline, from the sociomateriality viewpoint.

\section{THE INVESTIGATION AND ITS CONTEXT}

Since the core of the current article lies on sociomateriality, a qualitative methodology was adopted to allow its extrapolation to the practice. An airline was chosen as research locus. The airline was called "Estrela" due to confidentiality matters. Estrela uses BA in the RM processes; besides, Estrela's selection for the study also relied on the fact that one of the authors - who was in charge of data collection - had close contact with key informants in the company and had worked for 14 years in other airlines in the past.

The RM sector - which applies BA - where data collection was performed is located in the company's headquarters. It houses sectors that act in RM: yield management - which is in charge of market optimization (it has thirteen analysts, three coordinators and one manager); strategy - which is in charge of report generation (it has five analysts, one coordinator and one manager); pricing - which is in charge of price setting (it has right analysts, one coordinator and one manager). These sectors share the room with the planning sector, which has straight interaction with other sectors and has multiple influence on them; therefore, it was included in data collection. The planning sector counts on fifteen analysts, three coordinators and two managers.

All areas are located in a wide and open room, without partitions between work stations. There is a wide screen TV set in the room showing the RM indicators. Each analyst has a desk top linked to two screens. Managers stay in the corners of the room, two managers share the same table, they turn their seats to analysts' work stations; coordinators stay together with analysts, since they have permanent interaction with them.

BA application at Estrela followed its typical use in airlines, i.e., analysts use it to better understand operation aspects such as overbooking, price discounts, and variations in service types for each Brazilian region or place in the world - these regions are identified as markets (Slack, Chambers \& Johnston, 2008). Analysts at Estrela act simultaneously in three market types: the competitive market - huge competition (hard to predict); the prevailing market - the company is a leader in that specific market (a little easier to predict); and the monopoly market - company exclusivity (the most predictable of them all). Analysts deal with these three predictability levels within a set of 12-15 markets; each analyst is in charge of one of these markets.

Data collection started in April 2017. Based on Liu and Maitlis (2010), it was finished in July 2017, when theoretical saturation was reached. This happened when additional data started to no longer contribute to the aim of the study. Data collection started through non-participatory observation, which, according to the authors, is marked by lack of observer's participation - it defines them as non-participants. Obviously, the presence of a stranger has some effect on the 
process, but it does not mean a direct participation, since these sectors deal with technical operations that have implications in their performance. Of the 128-observation hours, 90 hours were dedicated to the yield sector, where BA use in RM is more common. In total, 28 hours were dedicated to the strategy sector; 7 hours, to the pricing sector; and 3 hours, to the planning sector.

The observation practice focused on the activities of one analyst at the time - the analysts were interviewed later on. These analysts were selected to help a coordinator from each area, and members from all areas, who should act in a given area - when it was under observation. Based on such criteria, the activities of two analysts or coordinators were observed in the morning other two analysts or coordinators were observed in the afternoon. When data saturation was reached, the activities of three coordinators in the sector were observed (one from each area), as well as of eleven yield analysts, our strategy analysts, and one pricing analyst. A field journal was written during the observation sessions; it totaled 82 pages. This data were completed with data from the explanatory and semi-structured interviews.

The exploratory interview was featured by not having a script (Quivy \& Campenhoudt, 2008) focused on getting information about the most general practices at the beginning of data collection. Participants selected during observation were asked to talk about their job descriptions at this research stage. It allowed interviewers to get familiar with the performed activities and with the used technologies.

The semi-structured interviews were carried out at the end of the observation sessions in order to clarify aspects highlighted throughout data collection. They were based on an initial and flexible guide-script that could be changed during the interview; they also focused on using the potential of interactions with interviewees (Robson, 2011). This script addressed technology use, learning and decision-making processes, and interaction types; it was also developed based on the collected data. The RM manager, one coordinator, and three analysts were interviewed at this research stage, as well as one manager from the planning sector. The analyst who was interviewed was in charge of developing the solution for the Business Intelligence (BI). Each one of these interviewees was selected during data collection due to their potential to provide more details about BA application to RM.

Each interview lasted approximately 30 minutes. Interviews were recorded and fully transcribed, except for the interview with the Planning Manager which was a written interview. The transcription resulted in 82 written pages. Interviewees in the following analysis were not identified due to privacy issues, they were identified by the word "Interviewee" followed by a number. Their features or specific personal contexts were not shown in separate given the small number of analysists in each area - specific features could allow their identification.

Documents highlighted by interviewees during the observation sessions and interviews, or the ones that were more often addressed by them, were collected through documental research. Reports often used in several sectors were selected, for example, the so-called trackers, analyzers, daily bookings, competitiveness reports, among others - In total, 20 pages of documents were gathered. The analysis applied to these reports allowed identifying the functionality and interactions of the technology which was used.

All data was treated based on the spiral analysis by Creswell (2013). Similar to a spiral, they were collected and organized in Word software, examined, classified and integrated; next, more data was collected, until saturation was reached. The framework developed by Bispo (2015) was adapted to guide the analysis, it was focused on the so-called Practice-Based Evidences (PBE), which was adapted to the sociomateriality approach by Leonardi $(2011,2012)$ in the current study. Leonardi advocates for the sociomateriality in the human/material dimension imbrication, 
which leads to the activities to the detriment of the idea of distributed dimensions in the BA practice. This concept turns the sociomaterial practice into the space for this imbrication process, as shown in Figure 1.

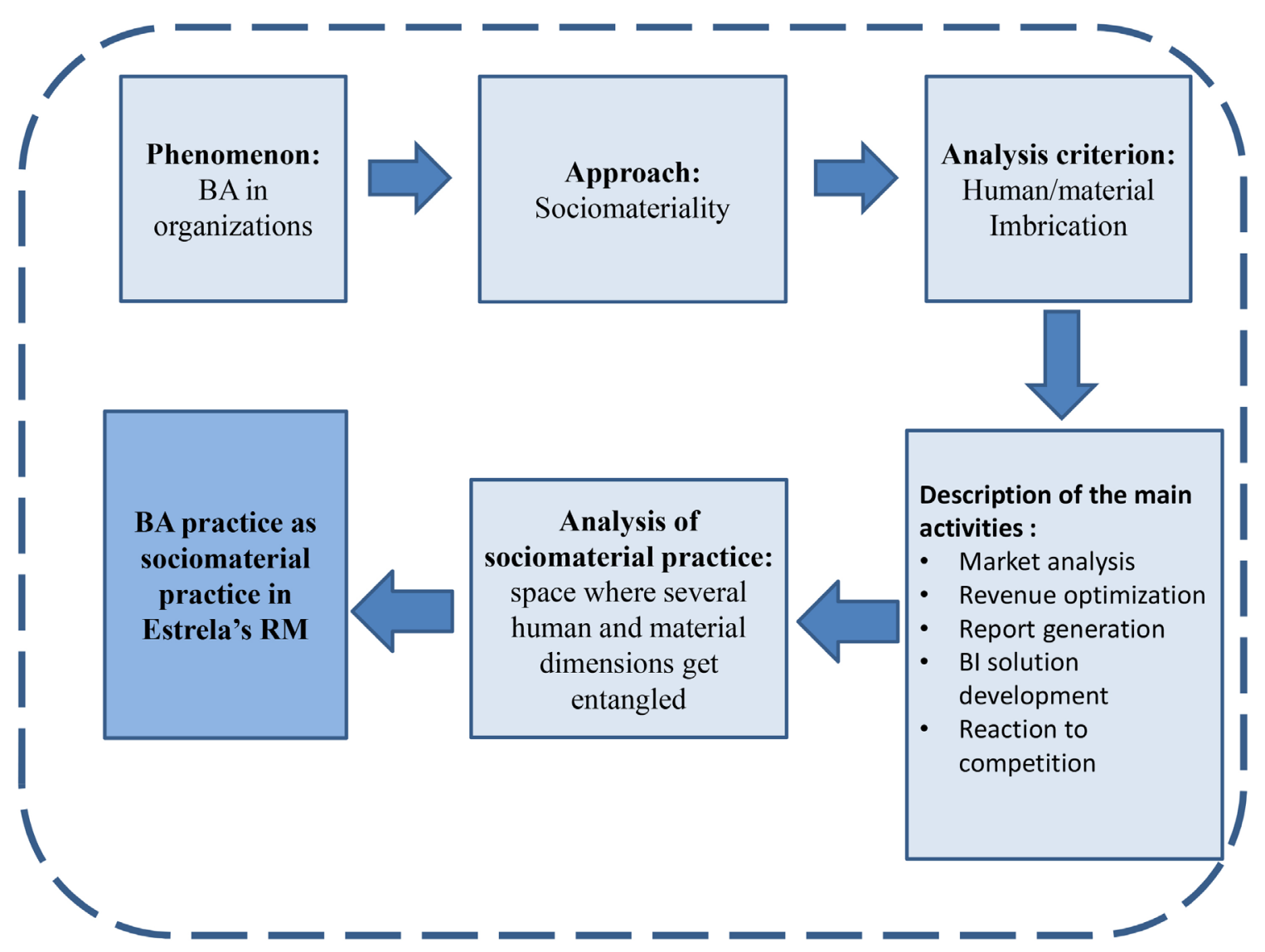

Figure 1. Framework for the analysis of BA sociomaterial practice in an organization.

Source: adapted from Bispo (2015), based on contributions by Leonardi (2011, 2012).

The analysis applied to these activities allowed showing the imbrications related to them, as well as the BA sociomaterial practice in Estrela's RM. Categories for data classification and organization (Creswell, 2013) have led to this evidence; they were gathered from the collected data themselves, namely: Market Analysis, Revenue Optimization, Report Generation, BI Solutions Development and Reaction to Competition. The topic described below makes a joint articulation with a set of aspects belonging to these categories - they were taken into account regardless of BA's sociomaterial practice.

\section{IMBRICATIONS IN THE BA'S SOCIOMATERIAL PRACTICE IN ESTRELA'S RM}

Based on the herein adopted concept, the sociomaterial practice is the space where several social and material dimensions get entangled in their relationship with the affordances and constraints of the material dimension (Leonardi, 2012). Therefore, by aiming at understanding the BA practice application to Estrela's RM, it was possible to describe the activities linked to 
such application in order to highlight the materiality of the involved technologies, as well as the affordances, constraints, and imbrications of dimensions related to them.

This materiality emerged from the expressions of the three perspectives linked to BA (Evans, 2016), namely: the descriptive, predictive, and prescriptive perspectives. The descriptive perspective is found in the investigated sectors based on performance diagnostics, which are presented in many of the used and generated reports. The Forecast report - which predicts revenue - is one example of BA's predictive profile in Estrela's BA. It is followed-up on a daily basis and supported by historical basis. BA's prescriptive perspective came along with the predictive one in the dynamics of the tracker spreadsheet. It is an electronic spreadsheet elaborated in Excel software and programed via VBA, which shows occupation and revenue planning, so that the yield analyst can predict market optimization. After seven days, when the analysist has total autonomy, this spreadsheet is called 'shape' and is used to make predictions and prescriptions about seat availability in different fare classes.

It was possible to identify a series of affordance and constraint manifestations related to spreadsheets used by the analysts. In the tracker spreadsheet, for example, an affordance received by a user is the interpretation that the material features in the spreadsheet can be changed within seven days; so, it gives autonomy to analysts to act freely, to make projections and changes in the spreadsheet's features. Many analysts have reported that it does not happen in a traditional RM system. Interviewee 2 reports this affordance:

Nowadays, we work with the tracker spreadsheet [...] it is an automatic and manual thing at the same time [...]. So, then, I see it as positive, because we need the people, I need people thinking, analyzing and not simply performing, because the great difference from great systems in airlines is just like that, the person generates in itself, parametrizes the system to work how he/she wants it to, what is necessary. The tracker spreadsheet is a little bit more flexible, and it helps us to work in a dynamic way.

Based on this affordance, the human Dimension - which was called 'people thinking' by the interviewee - is entangled to the material dimension and leads to changes in the tracker spreadsheet. Besides this affordance, any constraints sent to the tracker spreadsheet is related too the information missing for analysts' decision-making - in a given moment, the analyst started to demand more information. This spreadsheet causes eventual changes in the routines depending on flight status, because there is the need of taking information from other reports or from competitor's websites. This process depicts the technology flexibility highlighted by Leonardi (2011). The previous definition that reports must be generated by each agent at Estrela makes the flexibility of BA's sociomaterial practice.

Strategy is the sector officially in charge of generating the aforementioned previous reports, it must help yield analysts' decision-making process in order to give support to other sectors. However, yield analysts oftentimes generate their own reports in order to complete the ones they receive. It was observed a few times:

\footnotetext{
The analyst in question has his or her own report, which was customized with all markets. He or she made some adaptations by depicting the company and the competitions' frequency [...]. (Field journal).

The analyst has developed his or her own report, which shows all his or her markets (connection rates, local rates, distance, routes where competitors' operate in and compete with its markets) (Field journal).
}

Although yield analysts generate their own reports based on previous reports, Strategy analysts are the ones who see affordances as the straight access to an Access/SQL database necessary for 
some reports. Similarly, they understand constraints as the time demanded by the information extraction mechanism, which limits reports' generation and updating within the established deadlines. Thus, Strategy analysts cannot deliver all information demanded by Yield analysts in their reports.

As for the Yield sector, technology materiality gives Yield analysts access to the booking system and to reports from the strategy, pricing, and planning sectors. Yield analysts can observe an affordance: subsidies to the analyses and generation of new reports, which are customized by these analysts themselves. The intention that features the human dimension, in its turn, makes analysts often use this subsidy, which comes from a constraint that is perceived from the interaction with information delivered by the technology's materiality - these are lack of important information in reports received by the analysts (the tracker spreadsheet). This process imposes changes in Yield analysts' routines, they start generating different reports as the consequence of dimension imbrications, a fact that can even lead to the excessive production of reports and demands time due to the applied technology; therefore, it is understood as a technology constraint. When the herein proposed approach unveils this dynamic, it also provides elements to help managers and analysts reasoning about, and interacting with, sociomaterial changes and their consequences.

It is possible to provide elements to help managers and analysts because the analysis of the BA sociomaterial practice allows understanding what makes the changes in the technology applied to it. According to Leonardi and Barley (2008), constraints and affordances in imbrications can change the routines. This possibility became clear when analysts' overload of reports was observed. According to some analysts, it could be mitigated by Power BI; in other words, they expect Power $\mathrm{BI}$ - a change in technology - to change their routines, to optimize their activities, and to deal with constraints at the aforementioned time interval, as it was reported:

I think that one of the things that happen most often in favor or against is time, we cannot perform all necessary activities through the day, so, if I lose time updating a report [...] [with Power $\mathrm{BI}] \mathrm{I}$ will gain this time [...] it is going to be very positive to have all this information in a single way, in a single search. (Interviewee 5).

Interviewees' expectation towards changes was clearly identified, but, at the time of data collection, Power BI was still in implementation process. Even though, it already concerned a material dimension featured by automatic information capture from different websites and sources - all information was made available in an integrated way. Figure 2, below, articulates this dimension and other aspects already used to illustrate the dynamics of BA sociomaterial practice in Estrela's RM.

The sociomaterial practice in Figure 2 is featured as the space for dimension imbrications, as described by de Leonardi (2012) and adopted in the current study. It is important to observe that there are many aspects described, so far, that were not shown in Figure 2, because it does not aim at repeating the already performed detailed description, but at showing the dynamics of the BA sociomaterial practice at Estrela, based on dimension imbrications that have triggered changes in the constraints and affordances of technology's materiality. Based on this figure, Yield analysts in Estrelas' RM have changed their routine (1) since they demanded more BA information to make decisions based on RM information provided by Strategy analysts in their reports. The intention to gather more information is a feature of the human dimension, which perceives it as a constraint (1) of the tracker spreadsheet technology - lack of information available. Such a gap in information led to the development of new Excel reports (a change in technology) (1). This change in technology has generated a concrete material feature that exists regardless of the 


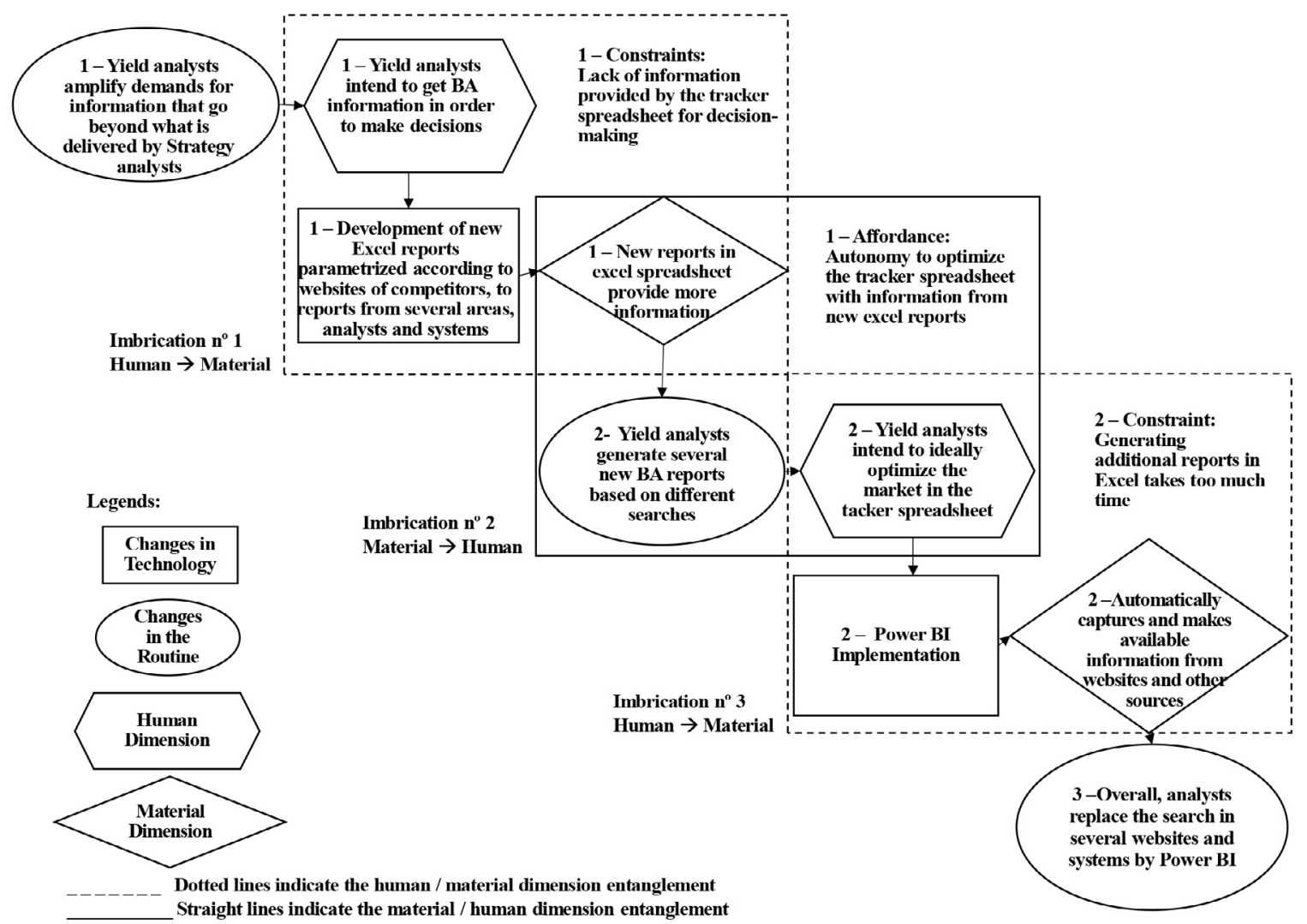

Figure 2. Example of dimension imbrications that have led to changes in routines and technologies due to the BA sociomaterial practice applied to Estrela's RM.

Source: Adapted from Leonardi (2011, p. 158), based on research data.

interpretation, namely: the ability of repots to produce more information. This process features the material dimension (1) imbrication (n.1) to the human dimension, which has started the whole process.

This material dimension (1), in its turn, refers to the affordance perception (1) of the technology, which allows these new data (in Excel reports - tracker spreadsheet) to be more often used to market optimization - the tracker spreadsheet is interpreted by the human dimension (1). This affordance (1) leads to routine changes (2), according to which, analysts start producing growing amounts of different new BA reports for RM application. A change marked by the material dimensions (1) imbrication (n.2) to the human dimension (2) is featured by the Yield analyst's intention to ideally optimize the market based on the tracker spreadsheet.

This human dimension (2), by interpreting the technology's material features, attribute to it the constraint (2) of additional reports in the Excel spreadsheet the demand for much time to be generated. This finding imposes the search for changes in technology (2), in the current case, Power BI's implementation - which remained in process at data collection stage. As soon as the implementation is complete, the sociomaterial practice dynamics will remain on-going, but, assumingly, with a new material feature for the technology - which will mark its material dimension (2): The Power BI System automatically captures information from competitors' websites, from the company's internal systems, among other sources, and makes this information available in an integrated way. This process would lead to other human/ material dimension 
imbrications (n. 3), which would lead to routine changes (3) - analysts would overall replace searches in websites and systems (to generate new reports for BA applied to RM) by Power BI use. However, such replacement must generate new interpretation about other affordances and constraints throughout time, within a perpetual process.

The dynamics observed in the BA sociomaterial practice applied to Estrela's RM is in compliance with the understanding by Leonardi (2012) and Pickering (2001), when they address that the coordinated human and material dimensions represent the capacity of action, but that 'intention' is only found in the human dimension. Besides, it is easy seeing the contribution from Leonardi (2011) to the field dedicated to studies about technology, which was brought to the BA-studies field. Based on the sociomaterial practice, the technology applied to BA for descriptive, predictive, and prescriptive purposes not only limits the social dimension, but also broadens its possibilities when it entangles to the material dimension.

One can observe that the human dimension has great potential to use the tracker spreadsheet to optimize the revenue, as it is the players' intention, within the 7-day time interval, when the analyst has total autonomy over it. After seven days, the tracker spreadsheet turns into the shape table and the dimension of the technology gets more intense in the material/social dimension imbrication boosted by the sociomaterial practice, which follows a pattern set in the past.

The imbrications make the role played by time in practices' production (Mutch, 2013) clear; therefore, imbrication analyses allow thinking about the process that turns the material into sociomaterial throughout time (Leonardi, 2011). Time is investigated in BA applied to RM, it is taken into consideration when it comes to the fastness in reacting to competition, within the time available to close the tracker spreadsheet, to responses to managers' requests by email or in person, to report updates and elaboration, among other daily activities. This chronological time is based on schedules and is seen by Schatzki (2006) and Nicolini (2007) as the objective time or, as stated by Schatzki, as the "time of the world". This time is part of an interviewed analyst's manifestations, who stated:

From the time I get to work, in the morning, I look at my emails from the previous day, then we have the tracker process, which is the first task of the day. As soon as someone generates a tracker, the first steps that I will take would be to optimize tomorrow's flights [...] we make this optimization and meanwhile I open other reports, daily bookings analyzer [...] (Interviewee 4).

Besides the objective time, there is the subjective time (Schatzki, 2006, Nicolini, 2007) of interpretations about deadlines. These interpretations of time raise the demanded differences - analysts deal with the chronological and objective times of the mentioned activities within these differences: they make certain reports and, simultaneously, justify the use of longer times or report simplification, among others.

Sociomaterial outcomes present time features such as rhythm and standardization, but they take place in instantaneous events, within an unpredictable time interval. The income of an urgent e-mail that takes analysts from their tasks is an example of an instantaneous event.

Dimensions and their imbrications in the BA sociomaterial practice are established within these temporal dynamics, as well as the symbolic constructions that relate to each other inside it, for instance, the different interpretations about the different profiles of RM analysts. Despite the profile competences, which label analysts' actions as aggressive or conservative in a timeless manner, it was possible to observe that this modus is placed in a timeline, in a materiality, and that it emerges from the dimensions' imbrication in the sociomateriality practice; therefore, it is not the exclusive condition of a human dimension. One of the analysts has revealed that: 
Aggressiveness or conservatism depend on the time of the year when I am working due to the market type I work in, on a daily basis, so there are times when I can be more aggressive, like now, July, high-demand vacation months, but in the rest of the year I use to be more conservative, because we do not have this much demand in order to get to better outcomes by being so aggressive, but each analyst has its own profile and I believe that my profile is a bit more conservative most of the time, I think that it goes against the flight types and markets we work with, as well. (Analyst E1).

Before and after indicating that she "believes" that the label is intrinsic to the practice, that it is timeless, the analyst associated the aspect placing such practice in a timeline and in materiality. The material dimension features the market type - prevailing, monopoly, and competition - described in the social context of action at Estrela, it becomes part of this context when it expresses itself in the imbrication of analysts' dimension to generate a label. In other words, the labeling process "to be more conservative or more aggressive" results from the imbrication of material aspects that highlight the association between the material dimension and the material dimension to label and to be labeled. Thus, the "new analysts" become more aggressive or more conservative based on the sociomaterial practice - this process expresses an endless "becoming" (Gherardi, 2012). According to DiMaggio (1997), people are not stuck to an automatic cognition, to a pattern that makes them more aggressive or more conservative, but the deliberation against such pattern is not usual; therefore, stereotypes that work as shortcuts to deal with aspects of work in daily life are common. According to this author, it is necessary to have a specific motivation, such as the inadequacy of patterns to deal with new stimuli, in order to beat deliberation. As for Estrela's case, analysts' aggressive and conservative patterns do not always work to deal with new issues or stimuli for BA application at Estrela's RM. This process encourages analysts to deliberate in order to find other forms of action, other work routines.

The evidence described above, as well as other herein introduced evidences, have shown that it is possible to understand and deal with social and material aspects that may or may not lead to changes in routines and technologies relates to BA, when they address it as a sociomaterial practice. This process takes place within a dynamic typical of the sociomaterial practice, which is unique in each organization, given the multiple imbrications possible. Such an outcome - and the set of herein listed elements - legitimizes the BA concept proposition advocated in the present study, which takes into consideration this sociometarial dynamics and broadens the horizon of this study field.

\section{CONCLUSION}

The aim of the current article was to understand the BA practice within the RM context in an airline, based on the sociomateriality viewpoint. The use of sociomateriality as the theoretical lens allowed us to evidence complex interactions in imbrications between dimensions in the BA practice applied to RM. This approach showed the relevance of going beyond the focus on strategy and of people as mere operators of such technology. These factors bring along some implications to the technology, and this statement is consensus in the BA-studies field.

The herein adopted approach allowed a close look over the reason why things remain as they always were and over the dynamics that leads to changes in social routines and in BA technology. Based on this look, the present study boosted advancements in the BA field due to the evidenced findings, which were followed by justifications substantiated by the sociomaterial viewpoint. 
When it comes to the contributions to the BA practice in organizations, the current proposition provided a way for affordances and constraints to be identified and addressed in organization contexts, in such a fashion to contribute to BA use. For example, this approach allowed identifying that the herein mentioned analyst has realized that she would gain time if she extracted information from previous BA reports. She also started using the technology available to search for new information when she realized that she was wasting time; she also realized that she could gather more information and make it available for others. Gains are affordances and losses are constraints, and both items are perceptions based on dimension imbrications. By recognizing such dynamics, the ones in charge of organizational management can become part of it by looking for changes in routines and technologies, through their human dimension, or by understanding that they must remain as they are, despite restrictions observed by the analysts, i.e., by seeing the sociomaterial practice as the space for material/social dimension imbrications. It is possible to see this dynamics and reason about planning, trainings, and other activities linked to these imbrications, as well as about what to do in order to take the affordances for granted and to deal with the constraints. Besides, the herein advocated hypothesis allows questioning the acceptance of simplistic labels that do not contribute to BA use. The labels given to analysts at Estrela "to be more aggressive or conservative" were unveiled by a continuous-production process that enabled questioning such labeling within managerial relationships. This process could be mitigated by broadening the discussion about this aspect from the sociomaterial viewpoint. This approach also made it possible to question the managerial attitude towards the implementation of new technologies, such as Power BI, which can be seen as a change in dimension imbrications throughout time, rather than just as one more technology operated by people.

All the herein mentioned aspects concern a key element of sociomateriality in the approach adopted in the current study, namely: time. This study has shown the time implications in sociomaterial production in BA practice by identifying the objective times in the RM field, such as deadlines set for certain tasks; and the subjective time of interpretations about these implications.

This time, and the sociomaterial-dynamics production itself, impaired the extrapolation of configurations specific of imbrications (identified for the airline) to other sectors. However, the contribution from the present study does not lie on such extrapolation, but on the theoretical and empirical acknowledgement about the sociomaterial relationship observed in conditions typical of BA use, such as its descriptive, predictive and prescriptive perspectives (Evans, 2016) and intensive use of the technology (Davenport \& Harris, 2007) addressed in previous studies. This relationship has not been deepened in this study field, but, yet, it is relevant.

In order to contribute to fulfiling this information gap, this article legitimates the current BA concept proposition, which acknowledged sociomateriality and addressed its potential to the ones interested in approaching this topic, based on the following viewpoint: BA is an active engagement process set between analysts and business managers within a sociomaterial imbrication, it is based on data and analytical tools used to find new insights. According to such concept, further studies about the topic can go deeper in different applications of BA sociomateriality.

However, it is important to observe that, despite the fact that the set of contributions was reached, they had a particular limitation: it was not possible having a participatory observation to broaden field approximation. In order to deal with these limitations, the option was made to broaden the data collection techniques, although there was a greater participatory potential in studying the practice, but it was not taken for granted in the present study. 
BBR

17

436

\section{REFERENCES}

Ashrafi, A., Ravasan, A., Trkman, P., \& Afshari, S. (2019) The role of business analytics capabilities in bolstering firms' agility and performance. International Journal of Information Management, $47,1-15$.

Aydiner, A., Tatoglu, E., Bayraktar, E., Zaim, S., \& Deleb, D. (2019). Business analytics and firm performance: The mediating role of business process performance. Journal of Business Research, 96, 228-237.

Barad, K. (2003). Posthumanist performativity: Toward an understanding of how matter comes to matter. Signs, 28(3), 801-831.

Bispo, M. S. (2015, July/September). Methodological Reflections on Practice-Based Research in Organization Studies. BAR - Brazilian Administration Review, 12(3), 309-323.

Bronzo, M., Resende, P.T. V. de, Oliveira, M. P. V. de, Mccormack, K., Sousa, P. R. de, \& Ferreira, R. L. (2013). Improving performance aligning business analytics with process orientation. International Journal of information management, 33, 300-307.

Cardoso, E. R. S., \& Silva, A. R. L. (2017). A Transformação Social de uma Ferramenta Estratégica em uma Organização Familiar Brasileira. Revista Eletrônica de Administração, 23(3), 173-205.

Chen, L., \& Nath, R. (2018). Business analytics maturity of firms: an examination of the relationships between managerial perception of IT, business analytics maturity and success. Information Systems Management, 35(1), 62-77.

Ciborra, C., \& Lanzara, G. F. (1994). Formative Contexts and ICT: Understanding the Dynamics of Innovation in Organizations. Accounting, Management and Information Technology, 4(2), 61-86.

Creswell, J. W. (2013). Qualitative Inquiry \& Research Design Choosing among Five Approaches (3rd ed.). Thousand Oaks, CA: SAGE.

Cross, R. (1997). Revenue Management: Hard-Core Tactics for Market Domination. New York, NY: Broadway Books.

Davenport, T.H. (2017, June). How Analytics Has Changed in the Last 10 Years (and How It's Stayed the Same). Harvard Business Review. https://hbr.org/2017/06/how-analytics-has-changed-in-thelast-10-years-and-how-its-stayed-the-same

Davenport, T. H., \& Harris, J. G. (2007). Competing on analytics: the new science of winning. Boston: Harvard Business School Press.

Davenport, T. H., Harris, J., Shapiro, J. (2010). Competing on Talent Analytics. Harvard Business Review, 88(10), 52-58.

DiMaggio, P. (1997). Culture and cognition. Annual review of sociology, 23(1), 263-287.

Donovan, A. W. (2005). Yield Management in the Airline Industry. Journal of Aviation/Aerospace Education \& Research, 14(3), 11-19. https://commons.erau.edu/jaaer/vol14/iss3/9

Dubey, R., Gunasekaran, A., Childe, S. J., \& Papadoupoulos, T. (2016). The impact of Big Data on world Class Sustainable Manufacturing. International Journal of Advanced Manufacturing Technology, 84(1), 631-645.

Evans, J.R. (2016). Business Analytics: Methods, Models and Decisions (2nd ed.). Pearson. 
Soejarto, A. \& Chandler, N. (2015, September 22). Magic Quadrant for Quadrant for Business Analytics Services, Worldwide. Gartner Research, G00269226. https://www.gartner.com/en/ documents/3135519/magic-quadrant-for-business-analytics-services-worldwide

Gherardi, S. (2012). How to conduct a practice-based study. Cheltenham: Edward Elgar.

Jordan, J., \& Ellen, C. (2009). Business need, data and business intelligence. Journal of Digital Asset Management, 5, 10-20.

Latour, B. (1999). On Recalling ANT (pp.15-25). In J. Law, \& J. Hassard (Eds.), Actor Network and After. Oxford: Blackwell and the Sociological Review.

Leonardi, P.M., \& Barley, S.R. (2008). Materiality and Change: Challenges to Building Better Theory about Technology and Organizing. Information and Organization, 18, 159-176.

Leonardi, P. M. (2011). When flexible routines meet flexible technologies: Affordance, constraint, and the imbrication of human and material agencies. MIS Quarterly, 35(1), 147-167.

Leonardi, P. M. (2012). Materiality, Sociomateriality, and Socio-Technical Systems: What Do These Terms Mean? How Are They Related? Do We Need Them? (pp. 25-48). In P. M. Leonardi, B. A. Nardi, \& J. Kallinikos (Eds.), Materiality and Organizing: Social Interaction in a Technological World. Oxford: Oxford University Press.

Leonardi, P.M. (2013). Theoretical foundations for the study of sociomateriality. Information and Organisation, 23(2), 59-76.

Liu, F., \& Maitlis, S. (2010). Nonparticipant Observation (pp. 610-612). In A. J. Mills, G. Durepos, \& E. Wiebe (Eds.), Encyclopedia of Case Study Research. Thousand Oaks, CA: Sage.

Majchrzak, A., \& Markus, M. (2012). Technology affordances and constraints in management information systems (MIS). In E. Kessler (Ed.), Encyclopedia of Management Theory. Forthcoming: Sage Publications.

Mutch, A. (2013). Sociomateriality: taking the wrong turning? Information Organization, 23(1), 28-40.

Netessine, S., \& Shumsky, R. (2002). Introduction to the Theory and Practice of yield Management. INFORMS Transactions on Education, 3(1), 34-44.

Nicolini, D. (2007). Stretching out and expanding work practices in time and space: The case of telemedicine. Human Relations, 60(6), 889-920.

Orlikowski, W. J. (2007). Sociomaterial practices: Exploring technology at work. Organization Studies, 28(9), 1435-1448.

Orlikowski, W. J. (2009). The sociomateriality of organisational life: considering technology in management research. Cambridge Journal of Economics, 34, 125-141.

Orlikowski, W. J., \& Scott, S.V. (2015). Exploring material-discursive practices. Journal of Management Studies, 52(5), 697-705.

Pickering, A. (1995). The mangle of practice: Time, agency, and science. Chicago: University of Chicago Press.

Pickering, A. (2001). Practice and posthumanism: Social theory and a history of agency (pp. 163174). In T. R. Schatzki, K. Knorr-Cetina, \& E. Vonsavigny. (Eds), The practice turn in contemporary theory. London: Routledge.

Quivy, R., \& Campenhoudt, L. (2008). Manual de Investigação em Ciências Sociais. Lisboa: Gradiva. 
BBR

17

438

Robson, C. (2011). Real World Research. Patstow, UK: Wiley.

Schatzki, T. R. (2006). On Organizations as They Happen. Organization Studies, 27(12), 1863-1873.

Sharma, R., Mithas, S., \& Kankanhalli, A. (2014). Transforming Decision-Making Processes: A Research Agenda for Understanding the Impact of Business Analytics on Organisations. European Journal of Information Systems, 23, 433-441.

Slack, N., Chambers, S., \& Johnston, R. (2008). Administração da produção. São Paulo: Atlas.

Strauss, A. K., Klein, R., \& Steinhardt, C. (2018). A review of choice-based revenue management: Theory and methods. European Journal of Operational Research, 271(2), 375-387.

Talluri, K. T., Ryzin, G.J. (2004). The Theory and Practice of Revenue Management. Berlin, Germany: Springer Science.

Trist, E. L., \& Bamforth, K. W. (1951). Some Social and Psychological Consequences of the Longwall Method of Coal-Getting. Human Relations, 4(1), 3-38.

Wang, Y., \& Byrd, T. (2017). Business analytics-enabled decision-making effectiveness through knowledge absorptive capacity in health care. Journal of Knowledge Management, 21(3), 517-539.

Zorina, A. P., \& Avison, D. (2011). When Environment Matters: Inter-Organizational Effects on Sociomaterial Imbrications and Change. In Proceedings of International Conference on Information Systems (pp.1-20). 